\title{
The Role of Propinquity and Coordination in Influencing Competitive Advantage of Retail SMEs in Malaysia
}

\author{
Nor Asmahani Ibrahim ${ }^{1}$, Rosmimah Roslin ${ }^{2}$ and Rozita Naina Mohamed ${ }^{2}$ \\ ${ }^{1}$ Faculty of Business and Management, Universiti Sultan Zainal Abidin, Terengganu, \\ Malaysia, \\ ${ }^{2}$ Faculty of Business and Management, Universiti Teknologi Mara, Shah Alam, Selangor, \\ Malaysia,
}

\begin{abstract}
The existence of hypermarkets and supermarkets with modern retail format has affected the performance of many retailers in the category of small medium enterprises (SMEs) in Malaysia. In this era of disruptive marketing, the main challenges of retail SMEs are the ability to survive, to remain competitive and to sustain the business. With the challenges of finding the right strategies to compete effectively, there is now an inclination to look at social networks as means of establishing strong market presence. Engaging and maintaining social networks in their business relationships is essential for retail SMEs if they want to address strategic positions and subsequently build strong competitive advantage in the business. This study postulates that establishing social networks, specifically in terms of propinquity (related with network cluster, network centrality and geographic proximity) among social network members, will enable the gathering of important resources needed by retail SMEs to secure more sustainable competitive advantage. However, only few studies have focused on social networks especially from the Asian context and many have overlooked the importance of social networks in retailing. This study also suggests the need to focus on coordination in relation to propinquity of social networks which refers to the location of retail SMEs and their ability to coordinate efforts to gain competitive advantage. This study extends the literature on social networks by providing a conceptual framework describing the importance of propinquity on coordination of activities leading to the development of competitive advantage for retail SMEs.
\end{abstract}

\section{Key words: Social networks, Propinquity, Retail SMEs, Coordination, Competitive advantage}

\section{INTRODUCTION}

For many countries, small-medium enterprises (SMEs) are the largest contributor of economic, political and social development. In Malaysia, the growth of retail SMEs can be seen through customer demands leading to the rise of revenue for the retail industry whilst there are diversity of retail formats such as hypermarkets, supermarkets and modern grocery stores from the year 1990 onwards [1]. Under the National Key Economic Areas (NKEA), retail and wholesale also provide the foundation to maximize contribution to the Gross National Income (GNI) of the country with the estimation of income around RM156 billion and providing a total of 454,190 new jobs by 2020 [2]. It is on this note that many countries rely on the development of SMEs because of their significant contribution in assisting the country's economic growth, social uplifting and political stability [3][4].

The Malaysian government has also placed much emphasis in facilitating the development of small businesses including the retail SMEs in order to ensure their sustainability and continued contribution to the country's socio-economic development. In line with the attention given by government, many programs have been developed by numerous government agencies to provide training, financial support and other relevant incentives to assist and monitor the development of SMEs in Malaysia. Despite many facilitating programs and funding given by the government, there are still daunting challenges faced by the SMEs in Malaysia. In retailing specifically, performance has decreased in 2015 (8.1\%) compared to 2014 (11.1\%). While in 2016, there was a slight increase

Corresponding Author: Nor Asmahani Ibrahim, Faculty of Business and Management, Universiti Sultan Zainal Abidin, Terengganu, Malaysia Email: nora_asmahani@yahoo.com 
of merely $7 \%$, making $17.8 \%$ increment in the retail trade [48]. It also recorded only $11.8 \%$ of retail trading in 2017 which is not significantly different from the previous year [48].

A substantial number of small retail businesses are still struggling in order to survive. The failure rate of small businesses is high compared to big businesses [5][6]. There are many factors contributing to these failures such as uncontrollable internal and external factors arising from personal attributes, management competencies, technical, skills and behavior of the owner-entrepreneurs [7]. It is therefore stressed that SMEs have to be innovative to achieve efficient growth by building and maintaining a network of partners [8]. Networks are vital for SMEs because they are often dependent on others as most SMEs acquire the resources from other entities [9]. It has been suggested that SMEs that are able to coordinate their business activities well, are more likely to succeed as SMEs that thrive are those with the ability to coordinate work with insufficient resources [10]. Thus, it is important for SMEs to develop strategic networking and develop alliances in order to attain superior business development as this could well be their competitive edge [11].

Unfortunately, not many researchers have related the importance of social networks as possible inputs for the development of competitive advantage. A social network understanding is that of propinquity which focuses on the proximity of social network members. The closer the members are located, the easier the exchange of business resources. Social networks are built on the principle that members within the network are more likely to help one another. From a business perspective, small retail enterprises, are more likely to draw support for their businesses from their social networks located near them [33]. Sharing of resources, knowledge and information are more likely to occur which may be essential for the business. Competitive advantage requires uniqueness in market positioning in order to attain returns that are above average [49]. Hence, it is essential to manage the contributing factors of competitive advantage in order to survive [50] such as the ability to offer differentiation that are difficult to imitate [51]. Thus, this proposed study believes that adapting the social network understanding of propinquity may lead to better coordination which ultimately ties to competitive advantage. The ability of small retail businesses to take advantage of their social network may enhance their coordinative efforts leading to long term competitive advantage.

\section{LITERATURE REVIEWS}

Networking is recognized as one of the important means of engaging with companies or individuals to establish long-term relationships. Networking is not a sudden commitment, but there must be mutual understanding and long term effort. In retail, networking is especially relevant for resourcegathering and resource-sharing purposes. It is on this note that social networks may be relevant as mutual understanding may be easier to achieve through such social circles. The benefits of having good social networks is the ability to gather valuable resources through access of information, material assistance, emotional support and new contact opportunities [12]. Networking itself plays a role to stimulate innovation and productivity [13], indeed, it is also a complementing factor in situations where cooperation is needed to achieve economies of scales as well as to integrate or merge skills, competencies and technologies [13].

Networking can be categorized into two; formal ties and informal ties [14]. Formal ties basically refer to companies that have connection with other parties including its business partners, government offices, and financial institutions to name a few. On the other hand, informal ties are related to social relationships between businesses and individuals, specifically with friends and family members [15]. Networks can be further identified by formal network, informal networks and social networks [16]. Informal relationships basically involve social relationships with relatives, friends, and acquaintances, while formal networks are concerned with relationships between actors that control business activities, such as relationships with customers, distributors, suppliers, competitors, and government. The perspective of social networks is the basis fundamental to the study of network relationships and the effect of networks that provide the foundation in describing and characterizing a firm's set of formal networks of relationships and organizational actions [17]. Social networks are essentially informal networks that can be used optimally in business relationships [52]. It is because of gaps in a web of relationships [18], or indirect ties connecting partners [19], or central locations in an industry structure [20], that social networks have not been used extensively in a business strategic setting.

The main understanding of social network is developed from Jacob Levy Moreno's study, (he is also known as Moreno) who was the important individual behind the evolvement of sociometry studies in the late 1970s. Moreno believed that individuals in any society extend their social networks with other people through a social structure [53]. The theory of social networks was developed by Bourdiew [22], extended and refined by Coleman [53] and Portes [35]. The analysis and practice of social network in entrepreneurship began in the 1980s [54]. Different with other types of 
network, social network relates to emotional support given to the business owner and basically the connection is based on the emotional relationship between friends [55], family, consultants and other entrepreneurs [53]. However, the past tradition of social networks has ignored the importance of physical space, even though the idea of place beneficial to understand innovation has wide credence. There is also evidence that shows the effect of proximity on the formation of network relationship [21][22]. Therefore, it is important for researchers to understand how propinquity of social networks benefits small businesses in order to gain business competitive advantage. Individuals are more likely to have connection, relationship, or friendship if they share similar connections [23]. This study is also closely linked to the notions of network cluster, network centrality and geographic proximity. Propinquity in social networks is related to the analysis of nodes at any levels where actors are likely to be connected when they are geographically close to one another. It is understood that the closer the individuals are located to each other, the more likely they are to form closer relationship. This understanding was supported by Belot \& Ermisch as they mentioned that geographically close individuals are more likely to be close friends [24]. There is also a study shown in a new housing project for World War II veterans living close to one another who were more likely to be friends because their housing units are near each other [25]. It is because individuals in corner housing units were more likely to be socially isolated as compared to individuals in units that lay between other units. For economist, propinquity is focused more on the cost of transportation compared to the actual number of miles between nodes in the networks [26]. This study believes that propinquity within networks has higher tendency for transferring and receiving valuable resources from other individuals or companies because of their closeness among each other.

Network cluster is also important for small business, even though industry cluster is different from network organizations [27], as companies within networks might be dispersed than industry cluster. It is deemed that relational closeness often occurs in networks which include the interactions between behavioral actors in the network. However, geographical proximity also can lead to relational closeness if participants in the industrial cluster commits to create and maintain close and mutual relationships with each other. The establishment of resource linkage between companies in a region is an ultimate reason for the occurrence of localized flow and transfers of knowledge [28]. Cluster companies are seen to enjoy uniformly asymmetric business competitive advantages than companies from outside the cluster [29]. However, this greatly vary in terms of transferring knowledge and assessing information among companies within the clusters [30]. Clustering also refers to the social networks which tend to have high density of close triads, where individuals are likely to become friends with the friends of their friends. Several rationales have been proposed to explain the universal observation that social networks exhibit nontrivial clustering. Therefore, this study postulates that network cluster also has similarities with propinquity as the geographical proximity highlighted within the cluster will only work if these cluster members are located near to each other. Those concentrated in the same location are able to participate in transferring resources, information and knowledge. In this respect, proximity in a social network is correlated with increased information about the trustworthiness of a potential contact.

In addition, network centrality explains the central position that will make it easier for network members to access diverse strategic resources for business, easier to form alliances with other companies and it also acts as mediators in integrating the knowledge and technology of other companies [30]. Furthermore, network centrality also makes it easier to plan innovative activities together by providing external information necessary to generate new ideas. Network centrality is also not only vital for engagement with outside company but also within organization. Occupying network position well makes it easy to access new knowledge by other units in the organization; for example, it will lead to more innovations for excellent business performance [31]. Essentially, established companies with higher network centrality have better access to valuable resources like information, skills and technology within the industry [32]. The main central positions in industrial networks facilitated the acquisition of essential technologies and market information. Thus, network position is closely related to the ability to gather resources, provides important new knowledge and also adds to the efficiency of resource utilization [31]. This study believes that propinquity of small retail business with their social network members whether geographically, centrally, or clustered, are more likely to gain valuable resources through organized coordination and therefore are able to enjoy competitive advantage. As such, the following framework is conceptualized:

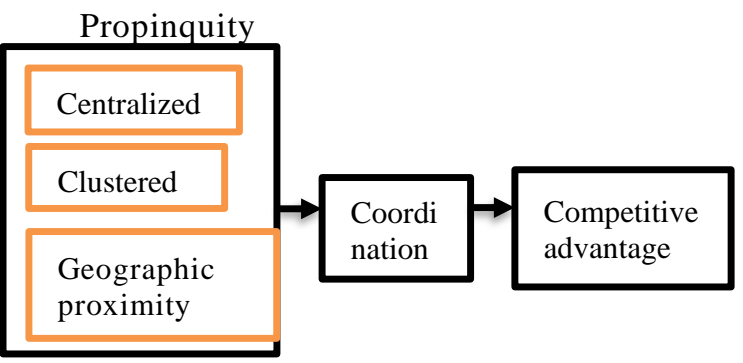


Figure 1. Conceptual framework of propinquity in social networks, coordination and competitive advantage of retail SMEs in Malaysia.

Based on the conceptual framework, this study postulates that:

$\mathrm{H} 1$ : A centralized propinquity in social networks has positive relationship with coordination of efforts to influence competitive advantage of retail SMEs.

$\mathrm{H} 2$ : A clustered propinquity in social networks has positive relationship with coordination of efforts to influence competitive advantage of retail SMEs.

H3: A geographic proximity of propinquity in social networks has positive relationship with coordination of efforts to influence competitive advantage of retail SMEs.

For retail SMEs, propinquity of social networks is very important to boost up coordination efforts in order to gain competitive advantage in the business. It is widely accepted that networks and business relationships lead to considerable impact to sustain and improve companies' competitive advantages [34]. Competitive advantage can be achieved through three strategies; a lower cost, focus and differentiation [35]. The advantages of a lower cost strategy is that companies will be able to operate more efficiently than its competitors, able to produce good quality of products and services to match market prices [35]. On the other hand, differentiation strategy is when companies are able to produce unique products and services, therefore it is difficult for rivals to copy and companies will be able to offer premium prices in the market [35]. The premium price can then enhance excellent returns for the companies [35]. Focus strategy is basically when companies focused on a narrow buyer segment and outcompeting rivals by having lower costs and customized attributes of products or services [35]. It can be understood that companies do not have to be the best player in the industry in order to gain competitive advantage; they just need to know how to create economic value for their products and services. Networking and clustering have the ability to improve SMEs competitiveness [36]. Even though networking is viewed as important for businesses success [37], clusters alone cannot solve the complex problems and difficulties faced by SMEs in breaking the vicious cycle of competitiveness [38]. The study of inter-firm relationships was extended by[39][40], showing that relationships are beyond the narrow dyadic focus and solely concentrated on collaborations as companies' strategic intention of growth strategy. It has been widely recognized that related companies and industries are likely to locate in geographical proximity to one another but concentrate on location only if agglomeration brings benefits greater than the cost of area [41]. Geographical advantages also relate to aspects of geographical location such as specialized labour and infrastructure. In essence, geographical proximity is seen as a driver that increases the sharing of knowledge and the development of institutions, which in turn give positive impact on cluster effectiveness. Geographical proximity also is able to create SMEs competitive advantages if these SMEs can effectively cooperate and compete with others since the linkage between cluster members results in the assumption that a whole is better than the sum of its parts [29].

In fact, competitors within a cluster also benefit from agglomeration effects that are able to lead to cost advantages and access to resources which is not available to competitors who are not located in the cluster [42][43]. The geographic concentration of clusters also contributes to the additional economic benefits and technology advantage [44]. Technological externalities can be described as the consequences of activity which directly influence the function of production in ways other than through the market [41]. Furthermore, geographical proximity also strengthened the communication efforts and intensifies the knowledge exchange between members in the cluster [45]. The cluster effects on competitiveness, indicates that belonging to a cluster has a strong positive effect on the policy of SMEs in industrialized countries [46]. It shows that geographical clustering of economic activity can give positive impact on a company's innovativeness, productiveness and competitiveness in many different ways [47]. Thus, it can be seen that companies in clusters can benefit from productivity improvements due to several reasons such as transaction costs of sharing and reducing, access to manpower, benefits associated with collective intelligence, the advancement and spillover of technology and increased competitive pressure.

\section{CONCLUSIONS}

This study provides a discussion of the social network theory of propinquity to stimulate social interaction and location factor in order to enhance network capabilities like coordination which in turn is capable in developing the competitive advantage of retail SMEs. Coordination is important to bring network members together in the channel in order to achieve the ultimate goal of the distribution network. Coordination also has the tendency to influence 
competitive advantage of retail SMEs in Malaysia as they need to work together in order to counter the aggressive advancement of large retail competitors. The unity of members in the channel of retail SMEs must be consistent in order to remain competitive in the market. It is hoped that this study will be able to gather more literature regarding the involvement of the retail SMEs in the distribution channel. Building and maintaining relationship among retail SMEs in the distribution channel is vital for survival and sustainability of retail SMEs to face tight competition from giant retailers. The understanding of ways to sustain retail SMEs also would be beneficial to the social, political and economic development of the country.

\section{REFERENCES}

[1] C.Y. Wong, L., Developments of Malaysia's Agricultural Sector: Agriculture as an engine of growth?,1-23(2007).

[2] Economic Transformation Programme. Annual Report 2012.

[3] Abdullah, M. A. \& Manan, S. K. A., Small and Medium Enterprises and Their Financing Patterns: Evidence from Malaysia, 32(2), 1-18 (2011).

[4] Khalique, M., Isa, A. H. B. M., Shaari, N., Abdul, J., \& Ageel, A., Challenges Faced by the Small and Medium Enterprises (SMEs) in Malaysia: An Intellectual Capital Perspective, 3(6), 398-401 (2011).

[5] Seeletse, S.M., Common causes of small businesses failure in the townships of West Rand district municipality in the Gauteng Province of South Africa, 6(44),1099411002(2012).

[6] Black,S., Fitzpatrick,A., Guttmann, R. \& Nicholls, S., The Financial Characteristics of Small Businesses, 25-32(2012).

[7] Karanja, T., Mutur, P., Mukab, M., Kabata, D.,Wahome, S. \& Kayogo, M. Small Business Management, 4, 16 (2013).

[8] Naude, Zaefarian, S.,Tavani, Neghabi, \& Zaefarian, R., The Influence on network effects on SME performance,43(4),630641 (2014).

[9] Farinda, A.G., Kamarulzaman, Y., Abdullah,A. \& Ahmad, S.Z.., Building Business Networking: A Proposed Framework for Malaysian SMEs, 5(2), 151160 (2009).

[10] Kowalkowski, Ch., Witell, L., \& Gustafsson, A., Any way goes: Identifying value constellations for service infusion in SMEs, 42 (1), 18-30 (2013)

[11] Taufik, S., Hening, W.O., Khuzaini \& Suwitho, The Influence of Strategic Alliance on Competitive Advantage through Market Area and Product Innovation, 8 (7), 57-72(2017).

[12] Sungmin,K. \& Youn, K.N., The Effect of the Relationship Characteristics and Social Capital of the Sharing Economy Business on the Social Network, Relationship Competitive Advantage, and Continuance Commitment, 10,2203 (2018).

[13] Mancinelli, S.\& Mazzanti, M., SME Performance, Innovation and Networking Evidence on Complementarities for a Local Economic System, 63, 1-27 (2007).

[14] Kontinen, T. \& Ojala, Network ties in the international opportunity recognition of family SMEs, 20(4), 440-453(2011).

[15] Hemmert, M. \& Kim, Jae-Jim, Informal Social Ties and Relationship Orientation in Korean Business Exchanges A Content Analysis of Ten Inter-Organizational Research Collaborations, 123 (2018).

[16] Chuairuang, S., Relational Networks and Family Firm Capital Structure in Thailand: Theory and Practice, 1-216 (2013).

[17] Ellis, P. \& Pecotich, A., Social factors influencing exportinitiation in small and medium-sized enterprises, 38(1), 119-130 (2001).

[18] Burt, R. S., Structural Holes: The Social Structure of Competition (1992).

[19] A. Pescosolido, B., The Sociology of Social Networks,208-217 (2006).

[20] Stuart, T.E., Interorganizational alliances and the performance of firms: a study of growth and innovation, 21 (8) 791$811(2000)$

[21] Sorenson, O., Social networks and the persistence of clusters: Evidence from the computer workstation industry, 1-20 (2004).

[22] Boschma, R. \& Frenken, K. The Spatial Evolution of Innovation Networks: A Proximity Perspective, 1-18(2009)

[23] McPherson, M., Smith-Lovin, L. \& M Cook, J., Birds Of A Feather: Homophily in Social Networks, 27, 415-444(2001).

[24] Belot, M. \& Ermisch, J., Friendship Ties and Geographical Mobility: Evidence from the BHPS, 2209, 1-31(2006).

[25].Kadushin, C., Introduction to Social Network Theory, 1-63(2004).

[26] Krugman, Paul R. \& Maurice, O., International Economics: Theory and Policy (2000).

[27] Giustiniano,L. \& Chiara D'alise, Networks, Clusters and Small Worlds: Are they related?, 4 (2), 48-53(2015).

[28] Rosenkopf, L., \& P. Almeida, Overcoming Local Search through Alliances and Mobility, 49(6), 751-766(2003). 
[29] Porter, M.E., Clusters and the New Economics of Competition, 76(6), 7790(1998).

[30] Giuliani, E., \& M. Bell, The MicroDeterminants of Meso-Level Learning and Innovation: Evidence from a Chilean Wine Cluster, 34(1), 47-68(2005).

[31] Tsai, W., Knowledge transfer in intraorganizational networks: effects of network position and absorptive capacity on business unit innovation and performance, 44(5), 9961004(2001).

[32] Aktamov, S. \& Zhao, Y., Impact of Network Centrality Positions on Innovation Performance of the Firm: Evidence from China Automobile Industry, 5(1), 164178(2014).

[33] Ibrahim, N.A. \& Roslin, R., Incorporating Social Networks in Business Relationships of Retail SMEs for Better Business Performance,7(4.38),1305-1309(2018).

[34] Acquaah, M., Business Strategy and Competitive Advantage in Family Businesses in Ghana: The Role of Social Networking Relationships, 1-35(2011).

[35] Thompson Jr. A., Peteraf, M., Gamble, J. \& A. Strickland, Crafting and Executing Strategy: The Quest for Competitive advantage, 134159(2018)

[36] Venkataramanaiah, S. \& Parashar, S. P. (2007), Enhancing the competitiveness of SMEs through industrial clusters: The Indian experience, 6(3), 227-243(2007).

[37] S. de Klerk, The importance of networking as a management skill, 41(1), 37-49(2010).

[38] Dasanayaka, S., Enhancing competitiveness of small medium scale industries through clusters, a case study based on Sri Lanka4248(2011).

[39] James,A., Gee,S., James H. Love, Roper,S. \& Willis, J., Small firm-large firm relationships and the implications for small firm innovation: what do we know?9,1-51(2014).

[40] Costa, E., Soares, A. L. \& de Sousa, J. P., Information, knowledge and collaboration management in the internationalisation of SMEs: A systematic literature review, 36(4), 557-569(2016).

[41] Martin, R. \& Sunley, P., Conceptualizing cluster evolution: Beyond the life cycle model?, 45(10), 1299-1318(2011).

[42] Menzel, P. \& Fornahl, D., Cluster life cycles Dimensions and rationales of cluster evolution, 19(1), 205-238(2010).
[43] Valdaliso, J. M., Elola, A., Aranguren, M. J., \& López, S., Social capital, internationalization and absorptive capacity: The electronics and ICT cluster of the Basque country, 23(9/10), 707-733(2011).

[44] Niu, K-H., Miles, G., Bach, S., \& Chinen, K., Trust, learning and a firm's involvement in industrial clusters: A conceptual framework, 22(2), 133-146 (2012).

[45] W. Heringaa, P., Horlingsa, E., Mariëlle van der Zouwenb, Peter van den Besselaard \& Vierssen, W.V., How do dimensions of proximity relate to the outcomes of collaboration? A survey of knowledgeintensive networks in the Dutch water sector, 23(7), 689-716 (2014)

[46] Zeinalnezhad, M., Muktar, M. \& Shahran,S., The Roll of Clusters and Networks in development of Industrial SME, 1,76-80 (2011).

[47] Sami Sultan, S., Enhancing the competitiveness of Palestinian SMEs through clustering, 9(2), 164-174 (2014).

[48] Ministry of Domestic Trade, Co-operatives and Consumerism, 2017.

[49] Breznik L., Can Information Technology be a Source of Competitive Advantage?, 14(3), 251-269(2012).

[50] Mukerjee K., Factors That Contribute Towards Competitive Advantage: A Conceptual Analysis, 26-39(2016).

[51] Dirisu, J.I., Iyiola, O. \& Ibidunni, O.S., Product Differentiation: A Tool Of Competitive Advantage And Optimal Organizational Performance (A Study Of Unilever Nigeria PLC), 9(34), 258281(2013).

[52] Gunto, M. \& Alias, M. H., The impact of networking on the SMEs' ability to access financial government support in Malaysia, 5(3), 9-17 (2014).

[53] Freeman, L. C., The Development of Social Network Analysis, 1-34(2004).

[54] Surin, E.F. \& Ab. Wahab, I., The Effect of Social Network on Business Performance in Established Manufacturing Small and Medium Enterprises (SMEs) in Malaysia, 67(12), 55-59(2013).

[55] Omwenga, J.Q., Mukulu, E. \& Kanali, C., Towards Improving the Performance of Women Entrepreneurs in Small and Medium Enterprises in Nairobi County, Kenya: Policy Recommendation, 4(9), 1-5(2013). 